\title{
Biomassa, proteína, colesterol e glicose extracelular de cinco isolados de Aspergillus flavus
}

\author{
Wencerly Ramos Rodrigues $J r^{l}$ \\ Tânia Andrade ${ }^{2}$ \\ Valdi Lopes Tutunji ${ }^{3}$
}

\begin{abstract}
RESUMO - Fungos filamentosos são organismos importantes para a produção de enzimas, compostos químicos e farmacêuticos. O comportamento metabólico comparado dos fungos é importante para conhecer suas relações taxonômicas e seu potencial uso em microbiologia industrial. Cinco isolados de Aspergillus flavus foram analisados quanto à produção de biomassa, proteína total, colesterol e glicose em diferentes meios de cultura e temperatura. Poucas diferenças foram observadas. Alguns isolados foram capazes de produzir quantidades significativas de colesterol sob as condições utilizadas neste estudo.
\end{abstract}

Palavras-chave: Aspergillus; biomassa; metabolismo; microbiologia industrial.

\section{Biomass, protein, cholesterol and extracellular glucose of five strains of Aspergillus flavus}

\begin{abstract}
Filamentous fungi are important organisms for the production of industrial enzymes, speciality chemicals and pharmaceuticals. Metabolic comparative behavior of fungi is important for the knowledge of their taxonomic relations and their potencial use in industrial microbiology. Five Aspergillus flavus strains were analyzed about biomass dry weight, total protein, cholesterol and glucose production in different culture media and temperature. Few differences were observed. Some strains are capable of producing significant amount of cholesterol in this study.
\end{abstract}

Key words: Aspergillus; biomass; metabolism; industrial microbiology.

${ }^{1}$ Graduando em Biomedicina do Centro Universitário de Brasília-UniCEUB.

${ }^{2}$ Bióloga, mestre em Biologia Molecular pela UnB, professora de Patologia Clínica I do CentroUniversitário deBrasília-UniCEUB.

${ }^{3}$ Biólogo, especialista em Saúde Pública pela ENSP/ FIOCRUZ, professor de Microbiologia, Bacteriologiae Micologia do Centro Universitário de Brasília-UniCEUB.E-mail: micoteca@uniceub.br

Univ. Ci. Saúde, Brasília, v. 3, n. 2, p. 249-252, jul./dez. 2005 
Fungos filamentosos são organismos importantes para a produção de enzimas, compostos químicos e farmacêuticos. Para produção de biomassa e conseguinte desenvolvimento de produtos com interesse industrial, deve-se exercer cuidadoso controle das condições de cultivo que permitam a atividade máxima do microorganismo disponibilizando nutrientes adequados e precavendo as modificações que possam ocorrer no meio pelo acúmulo de excretas que podem tornarse tóxicos ${ }^{1}$.

O conhecimento do comportamento metabólico comparado de diferentes isolados de mesma espécie de fungo, em meios e temperaturas diferentes, permite a descoberta de novas cepas com atividade metabólica de grande importância em microbiologia industrial ${ }^{2}$. O objetivo do presente trabalho é caracterizar o comportamento bioquímico relacionado à produção de biomassa e de diferentes metabólitos (proteínas totais, glicose e colesterol).

\section{Materiais e Métodos}

Cinco isolados de Aspergillus flavus, provenientes da Micoteca do UniCEUB, foram semeados em meio CSA - Czapek Dox Agar (nitrato de sódio 2g; fosfato de potássio dibásico $1 \mathrm{~g}$; sulfato de magnésio $0,5 \mathrm{~g}$; cloreto de potássio $0,5 \mathrm{~g}$; sulfato ferroso 0,01g; ágar 15g; água destilada 1000ml).

Após 14 dias de incubação em temperatura ambiente, cada um dos isolados foi repicado em duplicata nos seguintes meios: CZB - Czapek Dox Broth (nitrato de sódio $2 \mathrm{~g}$; fosfato de potássio dibásico $1 \mathrm{~g}$; sulfato de magnésio $0,5 \mathrm{~g}$; cloreto de potássio 0,5g; sulfato ferroso 0,01g; água destilada 1000ml) e C2S - Czapek Dox Broth, com $20 \%$ de sacarose e incubados, em temperatura ambiente a $35^{\circ} \mathrm{C}$.

Após mais sete dias, cada um dos caldos foi filtrado em papel-filtro para determinação do peso seco da biomassa. No filtrado, foram realizadas dosagens colorimétricas de proteínas totais (Doles lote PROA 2091), glicose (Labtest lote 4080) e colesterol (Katal lote 2505/05A). Todo o processo foi realizado em triplicata.

\section{Resultados}

Os dados estão apresentados na tabela 1.

\footnotetext{
${ }^{1}$ DAVID, 2003; CALVO, 2002.

${ }^{2}$ ROITMAN, 1988 . 
Atividade metabólica de Aspergillus flavus

Tabela 1 - Resultados das análises dos isolados em diferentes meios e temperaturas. CZB Czapek Dox Broth; C2S - Czapek Dox Broth com sacarose $20 \%$.

\begin{tabular}{|c|c|c|c|c|c|c|c|c|c|c|c|c|c|}
\hline \multirow{2}{*}{$\begin{array}{c}\text { Meio / } \\
\text { Temperatura }\end{array}$} & \multirow{2}{*}{$\underset{\text { tras }}{\text { Amos- }}$} & \multicolumn{3}{|c|}{$\underset{(\mathrm{g})}{\operatorname{Biomassa}}$} & \multicolumn{3}{|c|}{$\begin{array}{l}\text { Proteinas totais } \\
(\mathrm{g} / \mathrm{dL})\end{array}$} & \multicolumn{3}{|c|}{$\begin{array}{l}\text { Glicose } \\
\text { (mg/dL) }\end{array}$} & \multicolumn{3}{|c|}{$\begin{array}{c}\text { colesterol } \\
(\mathrm{mg} / \mathrm{dL})\end{array}$} \\
\hline & & $\mathrm{T} 1$ & $\mathrm{~T} 2$ & $\mathrm{~T} 3$ & $\mathrm{~T} 1$ & $\mathrm{~T} 2$ & $\mathrm{~T} 3$ & $\mathrm{~T} 1$ & $\mathrm{~T} 2$ & $\mathrm{~T} 3$ & $\mathrm{~T} 1$ & $\mathrm{~T} 2$ & $\mathrm{~T} 3$ \\
\hline \multirow{5}{*}{$\begin{array}{c}\text { CZB / } \\
\text { AMBIENTE }\end{array}$} & 1 & 0,007 & 0,02 & 0,018 & 0,0 & 0,0 & 0,0 & 0,0 & 0,0 & 0,0 & 0,0 & 0,0 & 0,0 \\
\hline & 2 & 0,002 & 0,019 & 0,018 & 0,0 & 0,0 & 0,0 & 0,0 & 0,0 & 0,0 & 0,0 & 0,0 & 2,6 \\
\hline & 3 & 0,004 & 0,019 & 0,02 & 0,0 & 0,0 & 0,0 & 0,0 & 0,0 & 0,0 & 0,0 & 0,0 & 2,2 \\
\hline & 4 & 0,009 & 0,021 & 0,016 & 0,0 & 0,0 & 0,0 & 1,5 & 0,0 & 0,0 & 0,0 & 0,0 & 1,8 \\
\hline & 5 & 0,006 & 0,014 & 0,015 & 0,0 & 0,0 & 0,0 & 0,0 & 0,0 & 0,0 & 0,0 & 0,0 & 1,3 \\
\hline \multirow{5}{*}{$\mathrm{CZB} / 35^{\circ} \mathrm{C}$} & 1 & 0,022 & 0,027 & 0,015 & 0,0 & 0,0 & 0,0 & 0,0 & 0,0 & 0,0 & 1,9 & 0,0 & 0,0 \\
\hline & 2 & 0,011 & 0,029 & 0,025 & 0,0 & 0,3 & 0,0 & 0,5 & 0,0 & 0,0 & 0,2 & 0,0 & 0,0 \\
\hline & 3 & 0,005 & 0,028 & 0,029 & 0,0 & 0,3 & 0,0 & 0,5 & 0,0 & 0,0 & 0,0 & 0,0 & 0,0 \\
\hline & 4 & 0,018 & 0,028 & 0,028 & 0,0 & 0,3 & 0,0 & 0,2 & 0,0 & 0,0 & 0,2 & 0,0 & 0,0 \\
\hline & 5 & 0,016 & 0,027 & 0,018 & 0,0 & 0,3 & 0,0 & 0,7 & 0,0 & 0,0 & 1,9 & 0,0 & 0,0 \\
\hline \multirow{5}{*}{$\begin{array}{c}\text { C2S / } \\
\text { AMBIENTE }\end{array}$} & 1 & 0,075 & 0,07 & 0,089 & 0,0 & 0,2 & 0,0 & 182,8 & 376,4 & 167,6 & 0,2 & 6,1 & 0,0 \\
\hline & 2 & 0,083 & 0,086 & 0,082 & 0,1 & 0,2 & 0,0 & 360,9 & 379,2 & 384,4 & 0,2 & 0,5 & 0,0 \\
\hline & 3 & 0,074 & 0,122 & 0,073 & 0,0 & 0,2 & 0,0 & 370,4 & 354,9 & 365,3 & 0,0 & 0,0 & 0,0 \\
\hline & 4 & 0,071 & 0,086 & 0,082 & 0,0 & 0,2 & 0,0 & 9,5 & 7,5 & 18,7 & 0,0 & 0,0 & 0,0 \\
\hline & 5 & 0,074 & 0,085 & 0,074 & 0,0 & 0,2 & 0,0 & 2,5 & 372,9 & 4,5 & 0,0 & 0,0 & 0,0 \\
\hline \multirow{5}{*}{$\mathrm{C} 2 \mathrm{~S} / 35^{\circ} \mathrm{C}$} & 1 & 0,058 & 0,095 & 0,089 & 0,1 & 0,1 & 0,0 & 370,9 & 372,4 & 402,6 & 1,4 & 0,0 & 0,9 \\
\hline & 2 & 0,089 & 0,087 & 0,083 & 0,2 & 0,1 & 0,0 & 363,7 & 377,4 & 398,3 & 1,4 & 0,0 & 0,9 \\
\hline & 3 & 0,083 & 0,078 & 0,07 & 0,1 & 0,1 & 0,1 & 371,6 & 379,9 & 417,9 & 0,2 & 0,5 & 0,4 \\
\hline & 4 & 0,088 & 0,087 & 0,075 & 0,0 & 0,0 & 0,0 & 53,2 & 5,3 & 85,2 & 0,2 & 0,0 & 0,0 \\
\hline & 5 & 0,065 & 0,076 & 0,069 & 0,1 & 0,1 & 0,0 & 362,4 & 474,7 & 193,5 & 2,9 & 1,0 & 3,5 \\
\hline
\end{tabular}

Univ. Ci. Saúde, Brasília, v. 3, n. 2, p. 249-252, jul./dez. 2005 


\section{Conclusão e Discussão}

Comparando os dados da tabela 1 , podemos verificar que a sacarose, tanto em temperatura ambiente quanto a $35^{\circ} \mathrm{C}$, é um estimulador para a produção de biomassa. Nas condições do experimento, as taxas de proteína após o período de incubação em diferentes temperaturas, adicionadas ou não de sacarose, não se mostraram significativas. Quanto ao aumento das taxas de glicose, podemos afirmar que são influenciadas pela temperatura de incubação. As taxas de colesterol apresentaram-se influenciadas tanto pelo substrato e pela temperatura de incubação.

Apesar de necessitar de número maior de testes, a metodologia apresentase potencialmente eficaz para detectar isolados com atividade metabólica de importância em microbiologia industrial.

\section{Referências}

CALVO, A. M etal. Relationship between Secondary Metabolism and Fungal Development. In: Microbiology and Molecular Biology Reviews 66(32):447-459. 2002

DAVID, H.; Akesson, M \& NIELSEN, J. Reconstruction of the central carbon metabolism of Aspergillus niger. In: Eur. J. Biochem. 270:4243-4253. 2003.

JERNEJC, K. \& CIMERMAN, A. Morphological Characteristics, Extracellular and Intracellular Protein and Enzime Patterns of Five Aspergillus Species. In: Food Technol. Biotechnol. 39(4):333-340. 2001.

ROITMANN, I. Tratado de microbiologia. São Paulo: Manole, 1988. 